\title{
Stability Analysis and Protection Measures of Large Section Tunnel in Coal Rich Weak Rock Stratum
}

\author{
Guannan Zhou, ${ }^{1}$ Zijiang Zhao $\mathbb{D}^{1},{ }^{1}$ Zhanping Song $\mathbb{D}^{2}{ }^{2}$ and Hongjian Wang ${ }^{3,4}$ \\ ${ }^{1}$ China Railway Bridge Engineering Bureau Group Co., Ltd., 300300 Tianjin, China \\ ${ }^{2}$ Xi'an University of Architecture and Technology, Xi'an, 710055 Shanxi, China \\ ${ }^{3}$ North China University of Water Resources and Electric Power, Zhengzhou, 450045 Henan, China \\ ${ }^{4}$ Zhongyuan Oilfield Branch of Sinopec, Puyang, 457000 Henan, China \\ Correspondence should be addressed to Zijiang Zhao; hanweige@stdu.edu.cn
}

Received 8 June 2021; Accepted 17 August 2021; Published 30 August 2021

Academic Editor: Yu Wang

Copyright (c) 2021 Guannan Zhou et al. This is an open access article distributed under the Creative Commons Attribution License, which permits unrestricted use, distribution, and reproduction in any medium, provided the original work is properly cited.

\begin{abstract}
Due to poor engineering geological conditions of Liujiazhuang tunnel on Shanghai-Kunming Passenger Dedicated Line, the large deformation of weak rock occurs repeatedly during tunnel construction. In this paper, the large-scale finite element software ABAQUS is used to simulate the construction process of a large-section tunnel in weak surrounding rock. It is found that when tunnel face passes through the coal seam, the displacement and stress simulated by the bench method increase abruptly. The maximum stress reaches up to $18 \mathrm{MPa}$, and displacement reaches $45 \mathrm{~mm}$, which is about twice when without crossing coal seam. It is technically feasible to use the bench method for tunnel construction, under the condition when large settlements is allowed; additionally, the bench method has better technical and economic benefits than that of the CD method. Through the comparative analysis of onsite monitoring data and numerical simulation results, it can be seen that the tunnel is in a dangerous state when passing through the coal seam and measures such as strengthening support or auxiliary advance support should be taken immediately to control the surrounding rock and to ensure tunnel construction safety.
\end{abstract}

\section{Introduction}

Due to many active faults, wide distribution of weak rock, high ground stress, karst development, and abundant groundwater, the tunnel in weak surrounding rock may produce many disasters such as large deformation, mud outburst and gushing water, collapsem and harmful gas [1-3]. By analyzing the characteristics of gas tunnel, the method of multihole cutting directional hydraulic fracturing to prevent gas outburst is proposed [4]. Shucai Li et al. studied the formation mechanism and development trend of karst tunnel water inrush disaster [5]. Zhang et al. conducted a systematic study on the occurrence mechanism and classification method of large deformation of structural weak rock in tunnel surrounding rock [6]. Wang et al. attributed the formation of the soft rock fracture zone of underground caverns to fatigue damage caused by repeated tectonic stress [ 7 ,
8]. At present, domestic and foreign methods for tunnel research in weak surrounding rock mainly include numerical simulation analysis, field monitoring measurement, and model test [9].

In weak rock tunnel stability theory analysis, Yang induced the factors affecting the stability of tunnel structure into four indexes, which are overbreak and underbreak volume, tunnel surrounding rock stability coefficient, the seismic intensity, and tunnel ratio. According to these four indices, original data information was collected; then by utilizing the information optimization theory, the relationship between the original data information and the stability of the tunnel structure is established [10]. Liu found that the cause of large deformation of the Muzhailing tunnel was resulting from the comprehensive action of surrounding rock plastic flow and surrounding rock swelling [11]. In recent years, Zuo et al. adopted the instability discriminant 
of surrounding rock obtained by the catastrophe theory and achieved satisfying results when analyzing the stability of surrounding rock in the fault section through which the tunnel passes [12]. Yong-Hao et al. obtained the elastoplastic mechanical parameters of rock mass through laboratory tests and Hoek-Brown criterion and obtained the rheological parameters of surrounding rock through finite element inversion analysis. Combined with tunnel deformation monitoring data, numerical simulation of large deformation behavior of tunnel thus was achieved [13]. Peng et al. established the calculation formula of RRC of weak rock roadway related to creep effect [14]. In terms of weak rock tunnel support, Li et al. took into account the rheological properties of surrounding rock and carried out viscoelastic analysis of surrounding rock on the basis of the Poyting-Thomoson model. Combined with the monitoring and measurement practice of the Shilong tunnel, the influence of initial support on the stability and displacement of surrounding rock was analyzed [15]. Liu et al. calculated the measured missing displacement according to the measured deformation statistics and the theoretical calculated limit displacement and elastic displacement, obtained the relationship between the measured deformation, the deformation rate before the secondary lining, and the limit displacement [16].

In terms of the physical model analysis of the stability of the weak rock tunnel, Tan et al. studied the displacement pressure of the tunnel with small clear distance in the initial supporting state by using the large-scale physical similarity model test [17]. Wang et al. established a calculation method suitable for prediction of ground subsidence caused by shield construction in weak rock area through indoor model test [18]. In terms of stability numerical calculation and analysis, Dai used numerical simulation to study the stability of shallow tunnel under different retaining schemes [19]. Yang et al. aimed at the influence of construction conditions, shallow burial, and other factors on the left portal of a tunnel, carried out three-dimensional simulation analysis by using numerical simulation, and compared the excavation methods [20]. Based on the numerical model and the improved strength reduction method, Chen et al. studied the influence of short bench, $\mathrm{CD}$, and CRD construction methods on the stability of large section loess tunnel crossing slope [21]. In terms of monitoring means, new methods are emerging continuously. Wu et al. studied the feasibility of the RA/AF ratio in describing the process of rock failure development [22]. Wang et al. studied the characteristics of acoustic emission parameters of layered shale and red sandstone under different fault modes, providing a basis for acoustic monitoring of surrounding rock stability in the field $[23,24]$. Hou et al. proposed a tunnel settlement inversion model based on distributed optical fiber strain [25]. Liu et al. applied dynamic parameterized 3D modeling technology into tunnel construction monitoring [26].

When tunnel traverses the soft surrounding rock section and large-section excavation construction technology that were carried out, unlike in the section with good geological conditions, rapid mechanized construction of tunnel lining can be used, and we must analyze the poor geological conditions of the section with weak surrounding rock, through comparative analysis of multiple construction technical plans, to obtain the optimist method. If merely in order to speed up the construction progress, blindly choose an inappropriate construction method, it will cause the tunnel excavation instability, on the contrary, delay the construction period and even cause engineering accidents. In this study, the Liujiazhuang tunnel passing through the weak coal seam group was taken as the engineering background, three construction methods were compared by numerical analysis, and the optimized one was obtained. In view of the large deformation problem caused by large section tunnel under such adverse geological conditions, the strengthening support measures are given.

\section{Engineering Background}

Liujiazhuang tunnel in Guizhou section of ShanghaiKunming Passenger dedicated railway is located in the middle and low mountainous area of erosion structure in Yungui Plateau. Influenced by the structure, the tunnel body is located in the area with relatively developed folds and faults, with broken rock mass and poor surrounding rock conditions. The $300 \mathrm{~m}$ section of tunnel D1K923+825 D1K924+125 passes through the weak coal seam with high gas content. The coal bearing stratum at the exit section of the Liujiazhuang tunnel is Longtan Formation of Permian upper series, and the lithology is mainly black mudstone, sandy mudstone, siltstone, fine sandstone, and limestone, with more than 20 layers of coal line, as shown in Figure 1.

According to the Code for design of railway tunnels in China (TB10003-2016), based on the basic classification of weak coal tunnel surrounding rock, combined with the groundwater state, initial in situ stress and occurrence of main structural planes in the coal tunnel section, the classification of tunnel surrounding rock in this section is determined as grade IV. The excavation method of class IV surrounding rock of the Liujiazhuang tunnel adopts the bench method and temporary cross bracing.

On March 8, 2012, the primary support arch of the tunnel exit section was seriously deformed, a large number of shotcretes fell off, the primary support shotcrete on site cracked, and the vault sank, as shown in Figure 2. The field monitoring and measurement data show that the maximum vault subsidence is $301 \mathrm{~mm}$, and the clearance convergence is $357 \mathrm{~mm}$. The steel frame was strengthened by adding anchor pipe with locking feet, but the effect was not good, and the initial support continued to deform.

Overall evaluation shows that the engineering geological conditions of tunnel body are poor, and large deformation of weak rock occurs many times during tunnel construction. When the tunnel passes through the weak coal seam, the numerical simulation analysis of the tunnel construction should be carried out and combined with the onsite monitoring measurement, and the monitoring measurement of the tunnel construction deformation and stability should be carried out. And the reasonable reinforcement and prevention measures should be put forward to ensure the safe construction of the tunnel. 


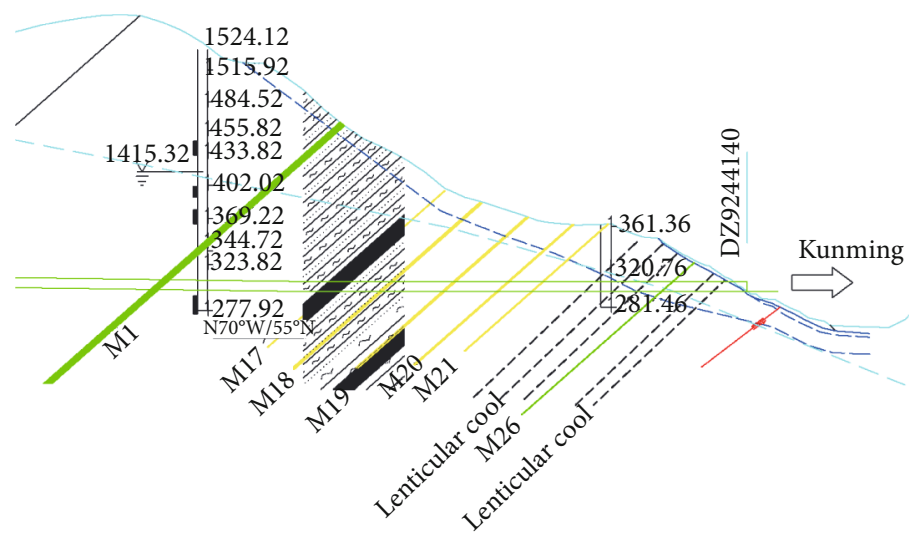

Figure 1: Profile of the Liujiazhuang tunnel.
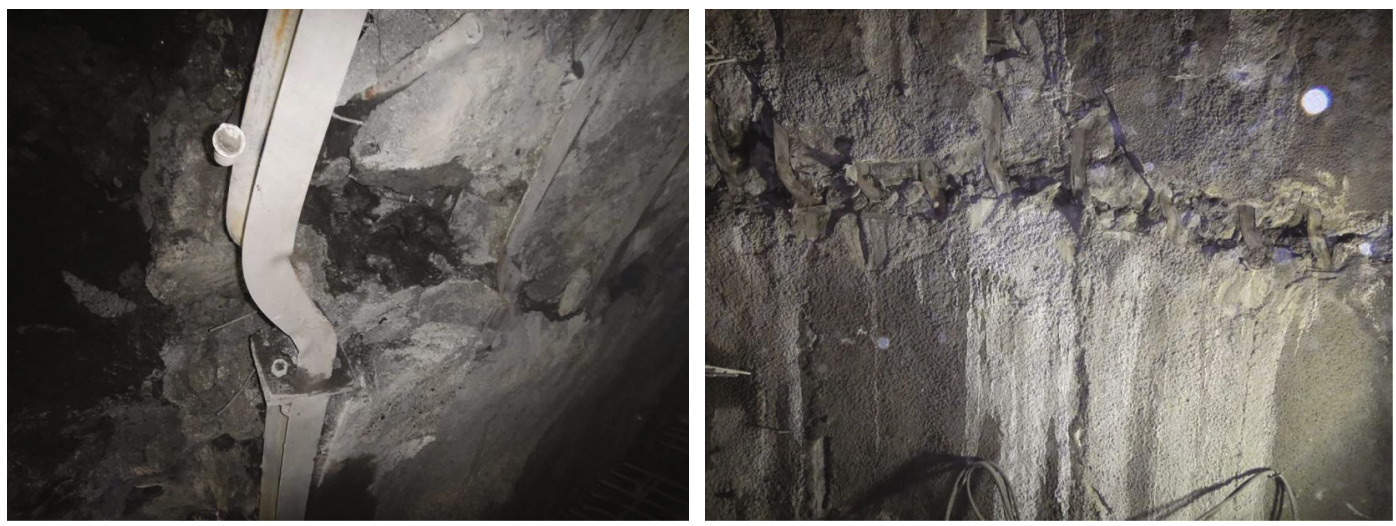

FIGURE 2: Distortion and spalling of shotcrete of steel frame for initial support of arch.

\section{Analysis of Mechanical Effect of Tunnel in Weak Surrounding Rock}

3.1. Large Deformation of Tunnel in Weak Surrounding Rock. The large deformation of weak surrounding rock is the key problem affecting the stability of surrounding rock. In order to analyze the mechanism of large deformation of tunnel in weak surrounding rock, the rubinite formula is introduced.

$$
\begin{aligned}
R_{P}= & R_{P 0}+R_{P 0} f(\theta) \\
= & R_{0}\left\{\frac{P_{0}(1+\lambda)+2 c \cot \phi(1-\sin \theta)}{2 P+2 c \cot \phi}\right\}^{1-\sin \phi / 2 \sin \phi} \\
& \times\left\{1+\frac{P_{0}(1-\lambda)(1-\sin \phi) \cos 2 \theta}{\left[P_{0}(1-\lambda)+2 c \cot \phi\right] \sin \phi}\right\}, \\
R_{P 0}= & R_{0}\left\{\frac{\left[P_{0}(1+\lambda)+2 c \cot \phi\right](1-\sin \phi)}{2 P+2 c \cot \phi}\right\}^{1-\sin \phi / 2 \sin \phi}, \\
f(\theta)= & \frac{P_{0}(1-\lambda)(1-\sin \phi) \cos 2 \theta}{\left[P_{0}(1-\lambda)+2 c \cot \phi\right] \sin \phi},
\end{aligned}
$$

where $R_{P}$ and $R_{0}$ are plastic zone radius (m) and tunnel radius $(\mathrm{m})$ of surrounding rock of circular tunnel, respec- tively. $R_{P 0}$ is the radius of axisymmetric plastic zone (m). $\theta$ is the angle between the polar radius of any point in the surrounding rock and the horizontal axis $\left(^{\circ}\right) ; f(\theta)$ is the relevant radius with $\theta$ of the plastic zone $(\mathrm{m}) ; P_{0}$ is the vertical initial geostress, which is considered as the self weight stress $(\mathrm{kPa})$; $\lambda$ is the horizontal initial geostress coefficient; $c$ and $\psi$ are the cohesion $(\mathrm{kPa})$ and internal friction angle of surrounding $\operatorname{rock}\left({ }^{\circ}\right)$, respectively; $P$ is the support force $(\mathrm{KN})$. Accordingly, the general elastic-plastic displacement of circular tunnel can be expressed by the formula:

$$
\begin{aligned}
U= & \frac{1}{4 G R_{0}}\left[R_{P 0}^{2}+(1+\lambda) R_{\mathrm{p} 0} f(\theta)\right] \cdot\left\{\sin \phi\left[(1+\lambda) P_{0}+2 \cot \phi\right]\right. \\
& \left.\cdot\left[1+\frac{(1-\lambda) \sin \phi}{R_{\mathrm{p} 0}(1-\sin \phi)} f(\theta)\right]-P_{0}(1-\lambda) \cos 2 \theta\right\},
\end{aligned}
$$

where $U$ is the displacement around the tunnel; $G$ is the shear modulus of surrounding rock. It can be seen from equation (4) that the main factors affecting the tunnel construction deformation include the initial geostress conditions (including the vertical geostress size and horizontal geostress coefficient), the properties of surrounding rock (including deformation parameters and strength index), 
and the tunnel size and support resistance. Among them, the horizontal geostress coefficient mainly determines the distribution of the plastic zone (the relative relationship between vertical deformation and horizontal deformation). For the convenience of analysis, assuming that the coefficient of lateral pressure is 1 , equations (1) and 4 are transformed into

$$
\begin{aligned}
& R_{P}=R_{0}\left\{\frac{\left[P_{0}+c \cot \phi\right](1-\sin \phi)}{P+c \cot \phi}\right\}^{1-\sin \phi / 2 \sin \phi}, \\
& U=\frac{R_{P}^{2}}{2 G R_{0}}\left(P_{0}+c \cot \phi\right) \sin \phi .
\end{aligned}
$$

It can be seen from equations (5) and (6) that the rock deformation around the tunnel is directly proportional to the square of the radius of the plastic zone. It can be seen that there will be a large range of plastic zone in the process of tunnel construction. The large range of plastic zone mainly depends on the strength index (especially the value) of surrounding rock, the value of in situ stress, and the resistance provided by the su-porting structure, as shown in equation (5). The general strength index of weak surrounding rock is relatively low, and it is easy to appear a large range of plastic zone under a certain level of in situ stress. If the support is not timely or the support measures are not appropriate, large deformation is bound to occur. It can be seen from equation (6) that the deformation around the tunnel is inversely proportional to the comprehensive deformation index shear modulus $G$ of surrounding rock. For the weak surrounding rock, its shear modulus is relatively low; so, the probability of large deformation in the corresponding tunnel construction deformation will increase. In addition, the tunnel excavation size is also one of the main factors of construction deformation. The larger the excavation size is, the more significant the construction deformation is.

3.2. Discrimination of Deep and Shallow Buried Tunnel. According to the Code for design of railway tunnels in China (TB10003-2016), the judgment standard for deep and shallow buried railway tunnels is $2.5 h_{q}$. The specific discrimination methods are as follows:

when $h \geq 2.5 h_{q}$, the tunnel is deep buried. When $h<$ $2.5 h_{q}$, the tunnel is shallow, where $h$ is the buried depth of tunnel vault. $h_{q}$ is the equivalent load height. The calculation method of $h_{q}$ is as follows:

$$
h_{q}=0.45 \times 2^{s-1} \times \omega .
$$

$s$ is the grade of surrounding rock. $\omega$ is the influence coefficient of tunnel width, and its value is

$$
\omega=1+i(B-5)
$$

where $B$ is the tunnel width (m); when $B>5 \mathrm{~m}, i=0.1$; when $B<5 \mathrm{~m}, i=0.2$.

In case of the Liujiazhuang tunnel, the ShanghaiKunming Passenger dedicated railway is a two-way high- speed line, the design section width of the tunnel is $B=12$ $\mathrm{m}$, the buried depth of the tunnel vault is $h=59 \mathrm{~m}$, and the surrounding rock grade of the Liujiazhuang tunnel passing through the coal seam section is $s=4$.

According to equations (7) and (8), $\omega=1.7$ and $h_{q}=$ $6.12 \mathrm{~m}$.

The buried depth of tunnel vault is $h=59 \mathrm{~m}>2.5 \times h_{q}$ $=2.5 \times 6.12=15.3 \mathrm{~m}$, and the Liujiazhuang tunnel is belonging to deep buried tunnel.

\section{Three-Dimensional Numerical Simulation Analysis of Large Cross-Section Tunnel in Weak Surrounding Rock}

In this chapter, the ABAQUS numerical software is used to simulate and analyze the construction process of the Liujiazhuang Tunnel in weak surrounding rock. The full-face excavation method, bench cut method, and CD method are used to optimize the tunnel construction scheme. Based on the numerical analysis, the tunnel construction deformation control technology is proposed.

4.1. Finite Element Analysis Software ABAQUS. ABAQUS is one of the most advanced finite element analysis software in the world. Rock, concrete, soil, and other materials are granular friction materials. The compressive yield strength of these materials is much greater than the tensile yield strength, and the particles will expand when the materials are in tension. Therefore, Drucker-Prager yield criterion is often used to simulate these materials. ABAQUS extends the classical Druker-Prager model. The yield surface of the extended Druker-Prager model is not circular on the plane, and the yield surface includes linear model, hyperbolic model, and exponential model on the meridian plane.

\subsection{Three Dimensional Numerical Simulation of Tunnel Construction Process}

\subsubsection{Model Parameter. In the calculation model,}

(1) The rock mass and weak coal seam are regarded as continuous, uniform, and isotropic elastic-plastic medium, and the stress-strain relationship of rock mass material is fully elastic-plastic without considering the influence of groundwater, and DrukerPrager yield criterion is adopted

(2) Only the stress field of the surrounding rock is considered, and the influence of the tectonic stress is not considered

(3) In order to simplify the calculation, the coal seam area is analyzed as a whole. In the whole excavation process, considering the role of the first lining, the secondary lining is only designed as a reserved safety reserve

According to the engineering geological data of the Liujiazhuang Tunnel and Code for design of railway tunnels in China (TB10003-2016), the material parameters of 
TABLE 1: Material parameters of surrounding rock.

\begin{tabular}{lccccc}
\hline Parameters & Bulk density $\left(\mathrm{KN} / \mathrm{m}^{3}\right)$ & Elastic modulus $(\mathrm{GPa})$ & Poisson's ratio & Cohesion $(\mathrm{kPa})$ & Internal friction angle $\left(^{\circ}\right)$ \\
\hline Surrounding rock & 22 & 1.295 & 0.3 & 280 & 45 \\
\hline
\end{tabular}

TABLE 2: Rock mass parameters of anchorage zone.

\begin{tabular}{lccccc}
\hline Parameters & Bulk density $\left(\mathrm{KN} / \mathrm{m}^{3}\right)$ & Elastic modulus $(\mathrm{GPa})$ & Poisson's ratio & Cohesion $(\mathrm{kPa})$ & Internal friction angle $\left(^{\circ}\right)$ \\
\hline Anchorage zone & 22 & 1.295 & 0.3 & 330 & 45 \\
\hline
\end{tabular}

TABle 3: Physical and mechanical parameters of surrounding rock layers.

\begin{tabular}{|c|c|c|c|c|c|}
\hline Parameters & Bulk density $\left(\mathrm{KN} / \mathrm{m}^{3}\right)$ & Elastic modulus (GPa) & Poisson's ratio & Cohesion $(\mathrm{kPa})$ & Internal friction angle $\left({ }^{\circ}\right)$ \\
\hline First level & 20 & 5.5 & 0.31 & 800 & 28.8 \\
\hline Second level & 22 & 7.2 & 0.30 & 810 & 26 \\
\hline Third level & 23 & 12.2 & 0.32 & 840 & 30 \\
\hline Fourth level & 22 & 11.2 & 0.31 & 740 & 27 \\
\hline Weak coal seam & 15 & 0.5 & 0.33 & 52 & 25.8 \\
\hline First lining & 25 & 20 & 0.2 & - & - \\
\hline Grouting reinforcement & 22 & 1.295 & 0.3 & 300 & 45 \\
\hline
\end{tabular}

surrounding rock mass used in numerical simulation are shown in Table 1.

In the calculation, the bolt element is not used, but the method of improving the parameters of bolt and solid surrounding rock is adopted to simulate the role of anchor. According to the literature, the mechanical performance of rock mass reinforced by bolt is improved. The compressive strength and bending strength of surrounding rock are also improved. The anchorage zone parameters used in numerical simulation are shown in Table 2.

To sum up, according to Design drawing of the Liujiazhuang Tunnel of Shang-hai-Kunming Passenger Dedicated Line and the current Code for design of railway tunnels in China (TB10003-2016), the material parameters of rock and soil mass simulated by the project are shown in Table 3.

4.2.2. Three Dimensional Numerical Model. The calculation range of numerical analysis shows that the transverse length of the whole model is $100 \mathrm{~m}$, the height is $190 \mathrm{~m}$, and the longitudinal length is $210 \mathrm{~m}$ ( $X$ direction is the vertical to the tunnel centerline, $Y$ direction is the gravity direction, and $Z$ direction is the tunnel centerline direction), which meets the requirements of finite element model calculation and analysis. The tunnel is parallel to the water discharge tunnel. When the tunnel is excavated, half of the excavation has been completed. Therefore, the calculation model of the Liujiazhuang Tunnel is shown in Figure 3. The model adopts solid element to simulate coal seam, lining, and rock mass. The hexahedral element mapping is used for the tunnel lining and the lining of the water discharge tunnel. The number of the units is 832 and 904 , and the number of nodes is 1650 and 560, respectively. Tetrahedral elements

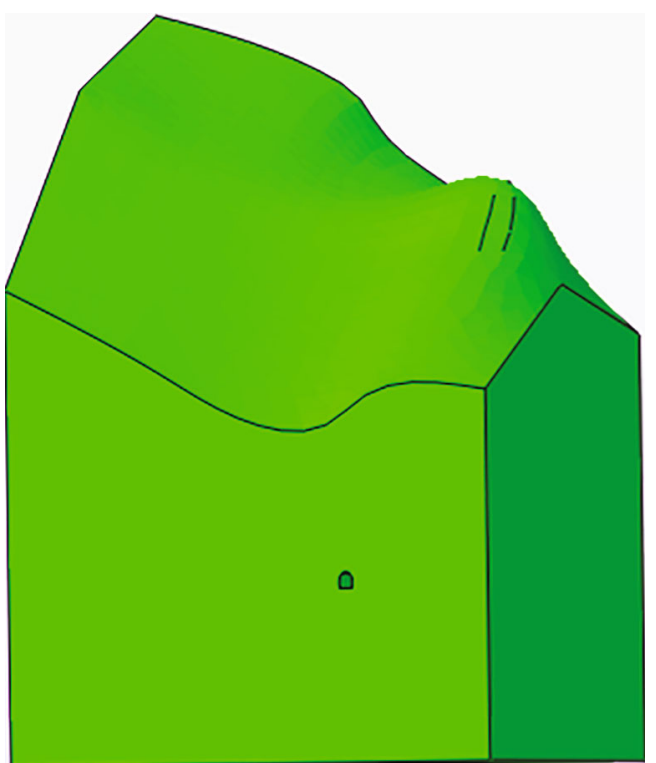

FIgURE 3: Mountain model.

are used to divide the mountain freely. The number of elements and nodes of the whole model is 62686 and 32269, respectively. The mesh is shown in Figure 4.

When meshing at the intersection of tunnel, drainage tunnel, and coal seam, irregular error unit and warning unit often appear. In order to reduce the proportion of wrong elements in meshing, hexahedral elements with neutral axis mapping are used for the excavation of tunnel rock mass and tunnel lining, discharge tunnel rock mass, and discharge tunnel lining. Tetrahedral elements are used for other areas 


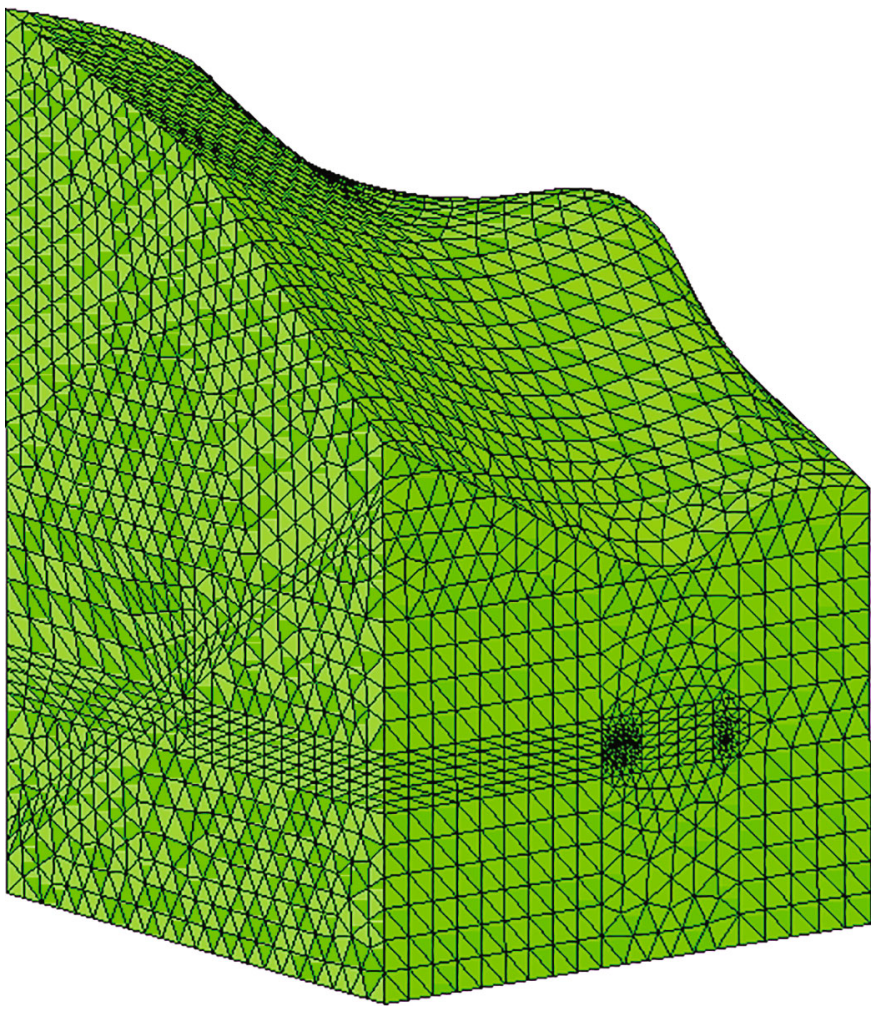

FIgURE 4: Grid graph.

of the mountain. The accuracy of mesh generation is greatly improved by planting seeds locally at intersections and modifying the size of mesh seeds, as shown in Figure 5.

\subsubsection{Numerical Calculation and Scheme Optimization of} Tunnel Construction through Coal Seam. The simulation steps of the numerical software are as follows: Firstly, set the initial stress of the model to balance the self-weight stress. Secondly, full-face excavation method, bench cut method, and CD method are used to simulate the tunnel excavation and support, respectively, and the stress and displacement of three different excavation methods are analyzed.

(1) Full-Face Excavation Method. The construction process of the tunnel is numerically simulated according to the construction steps of full-face excavation method, and the stress diagram and displacement diagram are shown in Figure 6.

It can be seen from Figures 6(a) and 6(b) that the stress concentration occurs after the excavation of the section. With implementation of the supporting structure, the stress distribution around the tunnel after the excavation is obviously improved, and the maximum stress is gradually transferred from the vault to the arch waist on both sides. After the excavation and support is completed, the maximum stress of the arch waist is $6.35 \mathrm{MPa}$. In the middle of the tunnel arch and invert, the stress is released more, the minimum principal stress value is $0.316 \mathrm{MPa}$, and the whole cal- culation area is in the compression state. It can be seen from Figures 6(c) and 6(d) that the surrounding rock of the tunnel moves towards the excavation chamber after the full-face excavation. The displacement of the horizontal direction of the surrounding rock is the largest at the arch waist, the vertical maximum settlement value of the arch is about $37.58 \mathrm{~mm}$, and the upward displacement of the tunnel bottom is $15.47 \mathrm{~mm}$. The displacement of gravity direction is obvious in the range of $20 \mathrm{~m}$ above the vault, which is about 1.6 times of the tunnel diameter. The stress and displacement of the excavated water release tunnel have little influence on the construction of the tunnel during the whole tunnel construction.

(2) Bench Cut Method. The construction process of the tunnel is numerically simulated according to the construction steps of the upper and lower step method, and the stress diagram and displacement diagram are shown in Figure 7.

It can be seen from Figures $7(a)$ and $7(b)$ that after the upper bench excavation, the stress concentration appears around the core soil of the upper half section, and the maximum principal stress value can reach $5.35 \mathrm{MPa}$. After the initial support, the concentrated stress is transferred to the surrounding of the tunnel. After the excavation of the current half section, the rock stress around the tunnel changes greatly. When the inverted arch is completed, the stress distribution around the tunnel is obviously improved after the excavation of the tunnel. The maximum stress is borne by the arch waist on both sides, and the maximum stress of 


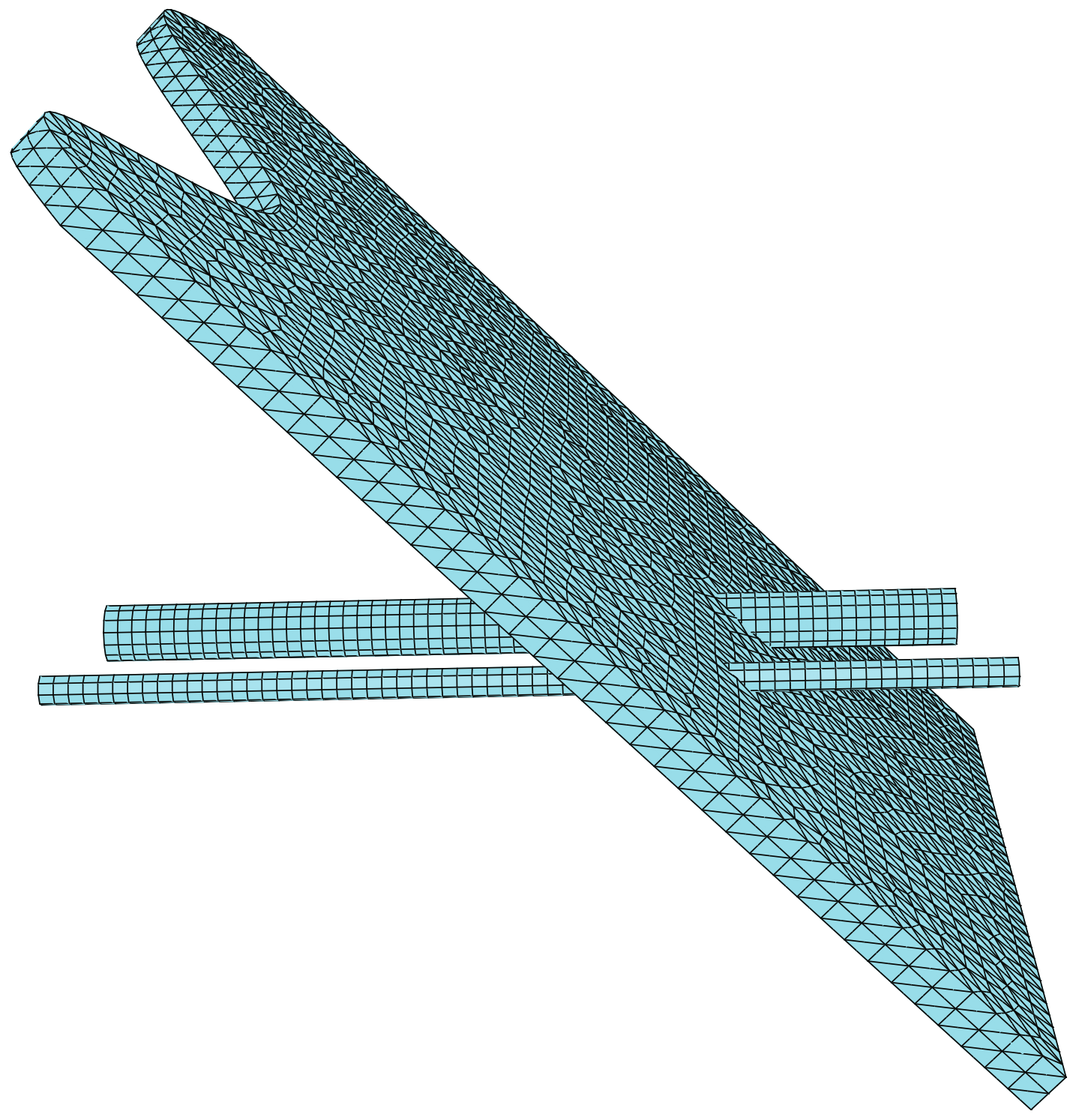

Figure 5: Cross diagram of coal seam and lining.

the arch waist is 7.20 MPa. At the top of tunnel and the bottom of invert, the stress is released more, the minimum stress is $0.57 \mathrm{MPa}$, and the whole calculation area is in the state of pressure.

It can be seen from Figures 7(c) and 7(d): after the excavation and support of the upper half section, the maximum horizontal displacement appears at the arch foot of the upper step, and the maximum displacement in the direction of gravity is at the vault of the tunnel. The maximum settlement of the vault of the tunnel is $17.13 \mathrm{~mm}$, and the upward displacement of the bottom of the tunnel is $5.14 \mathrm{~mm}$. After the excavation and support of the lower half section, the horizontal displacement of the surrounding rock basically does not change, and the vertical displacement changes significantly. The maximum settlement of the vault is about $20.93 \mathrm{~mm}$, and the bottom edge rises $8.03 \mathrm{~mm}$ upward. The vertical displacement within $15 \mathrm{~m}$ above the vault is obvious, which is about 1.2 times of the tunnel radius.
In the whole process of tunnel construction, the stress and displacement of the excavated tunnel have little influence on the tunnel construction.

(3) CD Method. The construction process of the tunnel is numerically simulated according to the construction steps of CD method, and the stress and displacement are shown in Figure 8.

From Figures $8(a)-8(d)$, it can be seen that (1) since the CD method adopts the excavation of side wall heading by parts, the self-weight stress field formed by this method is asymmetric. When the upper right half of the tunnel is excavated and supported, the stress concentration occurs at the junction of the excavation face, and the maximum value is 3.84 MPa. (2) After the excavation and support of the lower right half section of the tunnel, the stress at the arch waist becomes uniform, and the maximum stress is $5.76 \mathrm{MPa}$. 


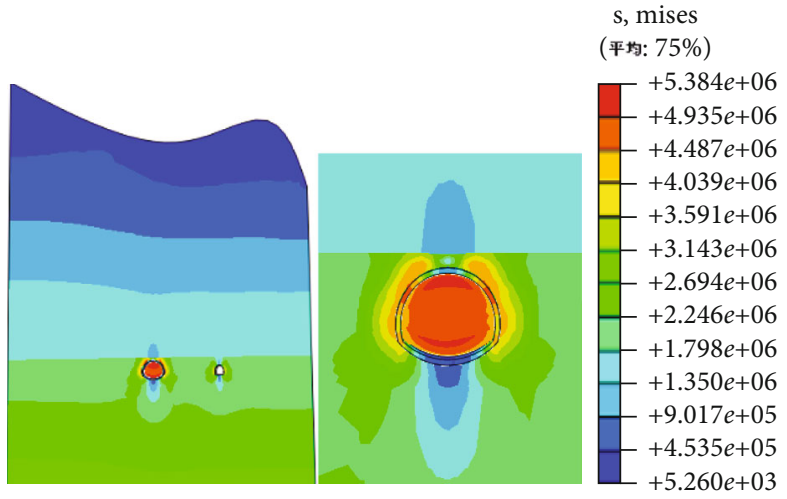

(a)

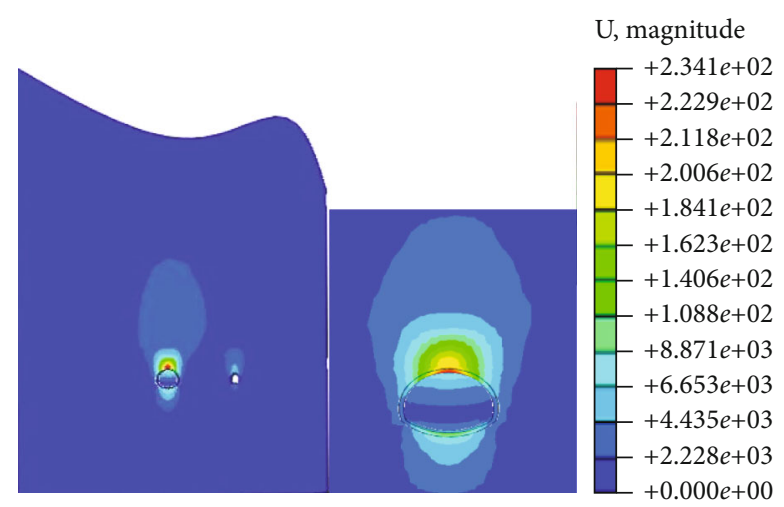

(c)

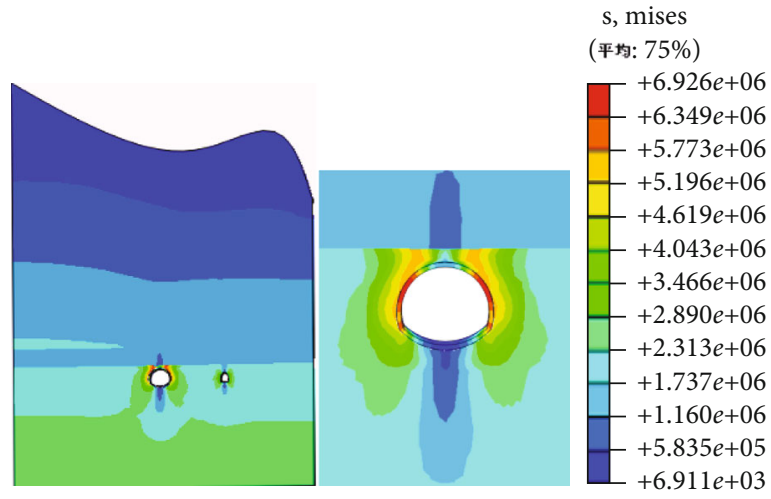

(b)

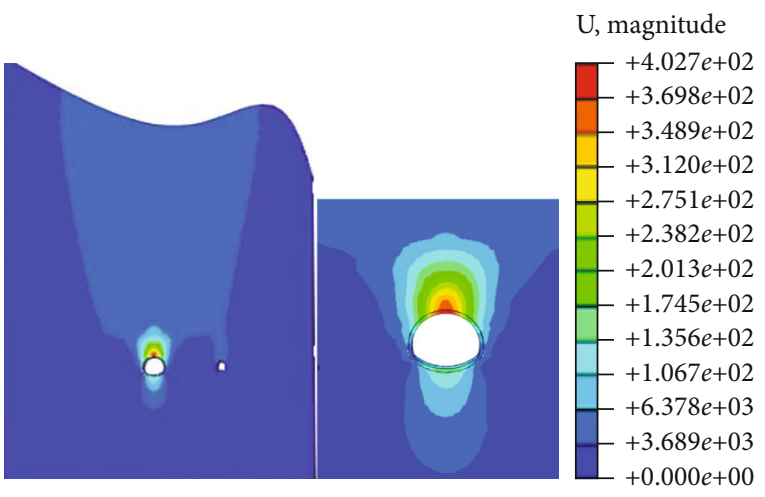

(d)

FIgURE 6: Stress diagram and displacement diagram of full section of tunnel crossing coal seam: (a) step 8: excavation stress diagram, (b) step 10: excavation stress diagram, (c) step 8: excavation displacement diagram, and (d) step 10: excavation displacement diagram.

(3) The stress of arch waist is the largest in the excavation of the upper left half section of the tunnel, with the value of 11.61 MPa. After support, only the stress concentration appears on the arch top, and the steel support also bears greater pressure. (4) After the excavation and support of the lower left half section of the tunnel, the stress field of the model is symmetrical, the maximum stress of the surrounding supporting structure is $18.52 \mathrm{MPa}$, and the surrounding rock and supporting structure of the tunnel are in the state of pressure. (5) The grid steel support can effectively limit the development of horizontal displacement. During the excavation process, the stress of surrounding rock changes significantly in the range of $3 \sim 4 \mathrm{~m}$ from the tunnel wall. After removing the grid steel support, the change of stress field is small, which indicates that the stress of surrounding rock has been basically released during the partial piloting of the CD method, and the deformation of tunnel is in a stable state.

From Figures $8(\mathrm{e})-8(\mathrm{~h})$, it can be seen that (1) the displacement field is asymmetrically distributed. After the excavation and support of the upper part of the heading, the displacement in the horizontal direction basically does not change, which is because the grid steel frame support plays a role in restraining the deformation. The vertical displacement increases obviously in the upper part of the heading before excavation. Because the vault is greatly constrained, the maximum settlement does not appear in the vault, but in the right side of the vault, about $4 \mathrm{~mm}$, the bottom rises $4.5 \mathrm{~mm}$. (2) After the excavation of the lower part of the heading, the horizontal displacement of the surrounding rock changes little, and the maximum vertical displacement is $9.7 \mathrm{~mm}$, which occurs in the middle of the excavation tunnel. (3) After the excavation and support of the upper part of the back heading, the displacement of the horizontal side wall is $2.51 \mathrm{~mm}$. The vertical displacement of vault and invert increased by $2.8 \mathrm{~mm}$, and the cumulative displacement reached $12.5 \mathrm{~mm}$, forming a " $U$ " shaped settlement trough above the excavation chamber. (4) After the excavation and support of the lower part of the back heading, the vault settlement displacement is $15.25 \mathrm{~mm}$, the invert displacement is $7.61 \mathrm{~mm}$, and the settlement tends to be stable. (5) After the middle diaphragm is removed, the displacement field is basically unchanged.

(4) Comparative Analysis of Numerical Simulation Results of Different Construction Methods. The stress and displacement of surrounding rock disturbed by the above excavation methods are compared and analyzed, as shown in Table 4.

It can be seen from Table 4 that (1) during the construction of full-face excavation method, the displacement around the cavern is the largest, and the stress is the smallest. The maximum stress of full-face excavation method is only 0.37 times of that of the CD excavation method. The 


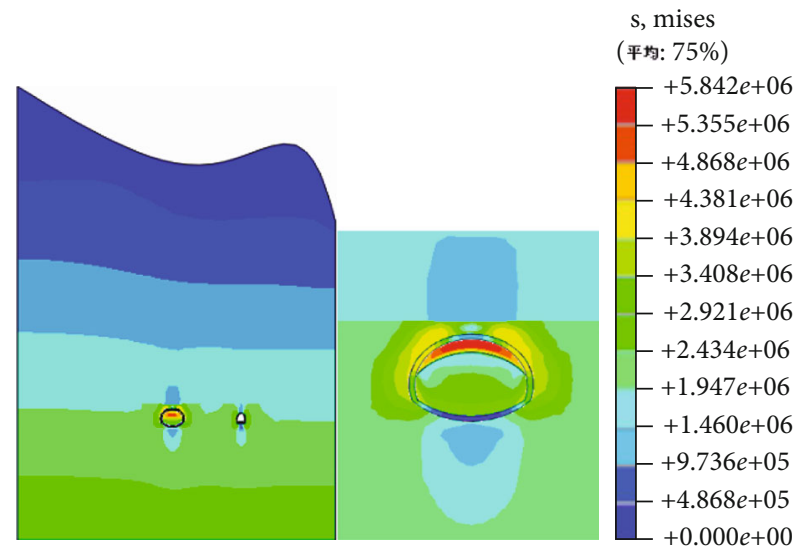

(a)

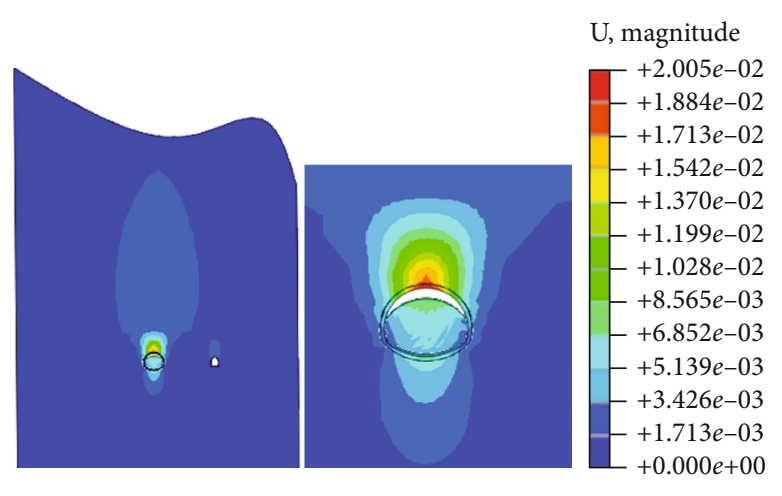

(c)

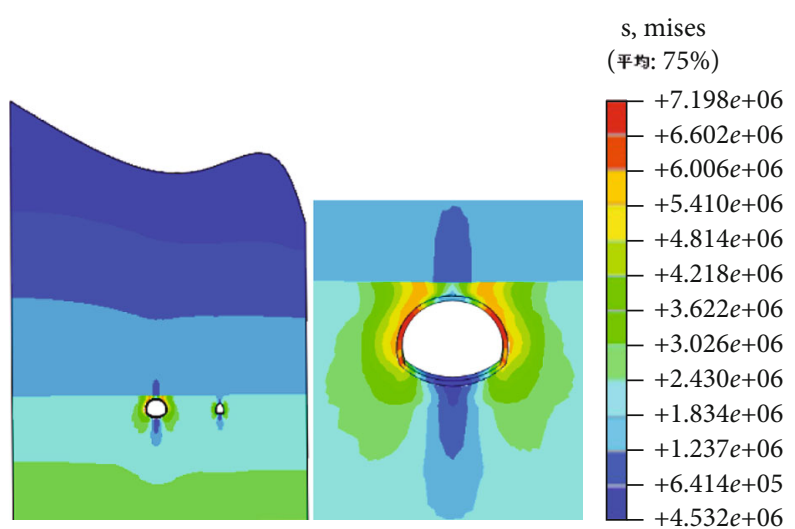

(b)

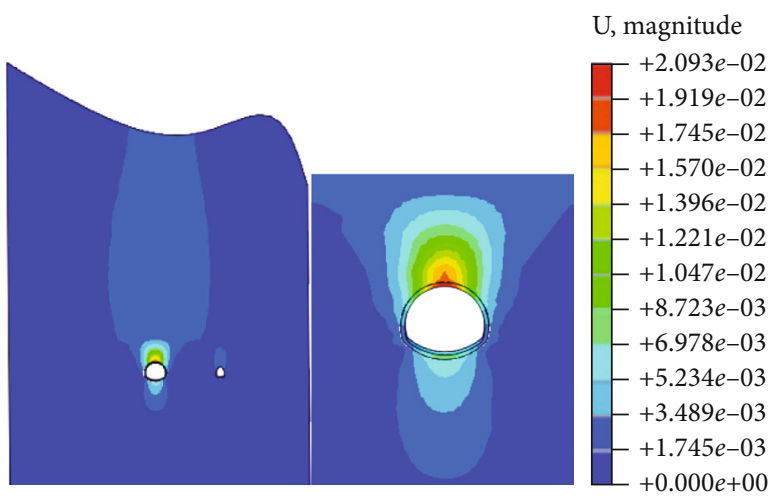

(d)

Figure 7: Stress diagram and displacement diagram of the upper and lower step method: (a) step 13: excavation stress diagram, (b) step 19: excavation stress diagram, (c) step 13: excavation displacement drawing and local enlarged drawing, and (d) step 19: excavation displacement diagram and partial enlarged drawing.

characteristics of full-face excavation method are small support stiffness, fast construction speed, and simple process; so, this method can be used in tunnel engineering which allowed large deformation. When facing the poor surrounding rock condition, in order to reduce the excavation step, increase the circulating footage, avoid unnecessary temporary support, and simplify the construction sequence, and most of the engineering personnel recommend using "advanced support with full section method" and using large machinery for full section excavation, so as to fully achieve the safe, fast, and efficient construction goal.

During the bench cut method, the displacement and stress around the cavern are between the full-face excavation method and the CD method. The analysis shows that construction process of the bench method is relatively simple compared with the $\mathrm{CD}$ method. By reserving the core soil behind the tunnel face, shortening the bench, closing the invert as close as possible to the tunnel face, and strengthening the arch foot support, the overall deformation of the middle arch of shallow buried weak surrounding rock tunnel can be controlled to varying degrees. However, the bench cut method has a greater disturbance to the weak surrounding rock in the excavation stage, and its ability to control the settlement deformation of shallow buried strata is far less than that of the CD method. The technology and economic benefit of the bench cut method is better than that of the CD method, which is suitable for medium grade surrounding rock. Therefore, for the construction of large section tunnel with weak surrounding rock, the reserved core soil bench cut method can be used when large surface settlement is allowed.

During the construction of the CD method, the displacement around the cavern is the smallest, and the stress is the largest. The maximum displacement of the CD method is only 0.46 times of that of the full-face excavation method and 0.75 times of that of the bench cut method. In the construction of weak surrounding rock, the CD method has no crossbracing, and the inverted arch of heading must be closed in time. Only after the support is closed can a strong overall support stiffness be formed, so as to control the clearance displacement in time for further development. The CD method is safe, but also is a slow and highly cost construction method. The results show that the CD method can be used when the tunnel span is large, the surface settlement is strict, and the surrounding rock condition is very poor and when it is difficult to control the deformation of surrounding rock by bench cut method.

Through the above comparative analysis, in the weak surrounding rock tunnel construction, the bench cut method has the advantages of simple construction technology, large 


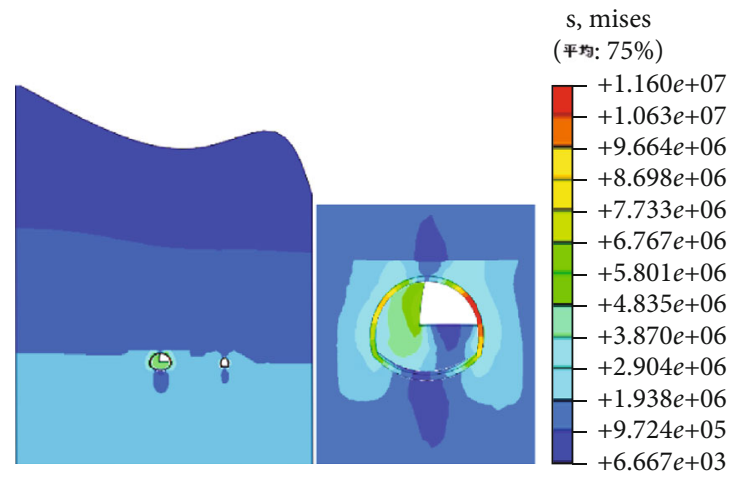

(a)

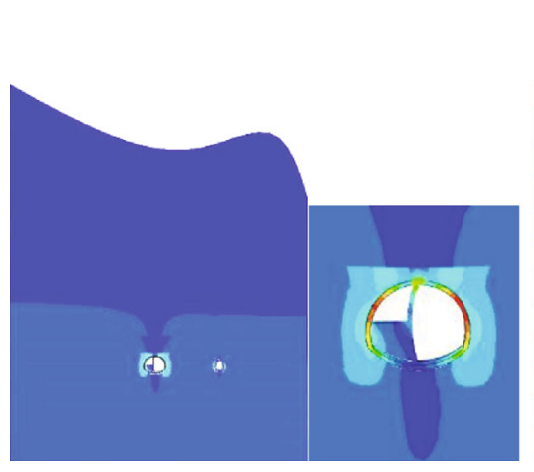

(c)

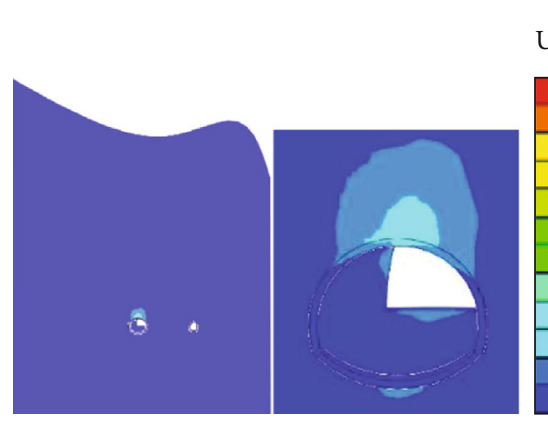

(e)

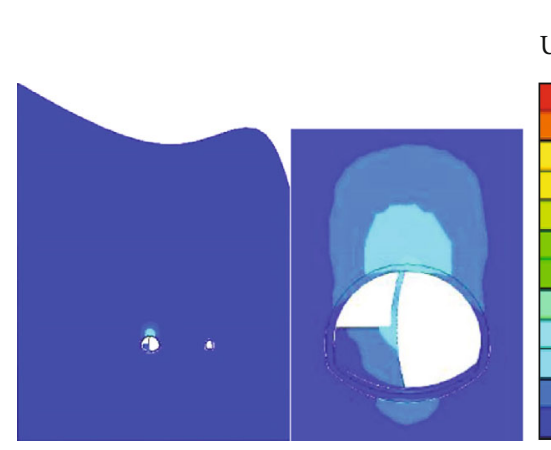

(g)

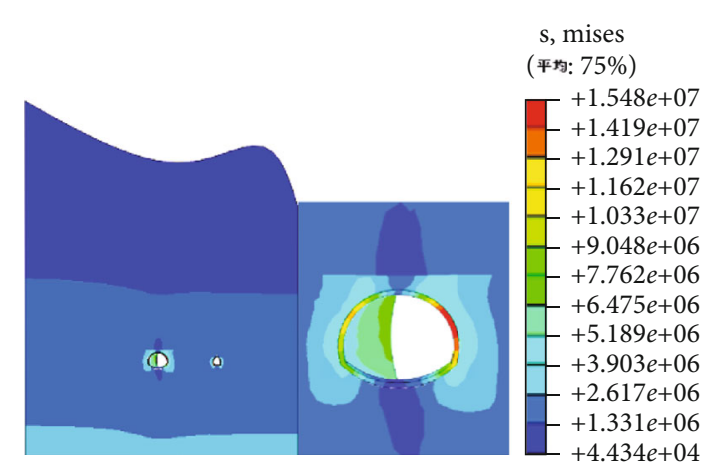

(b)

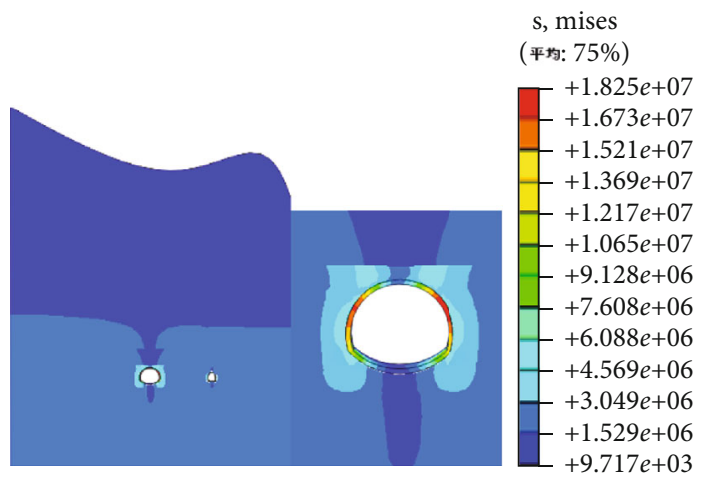

(d)
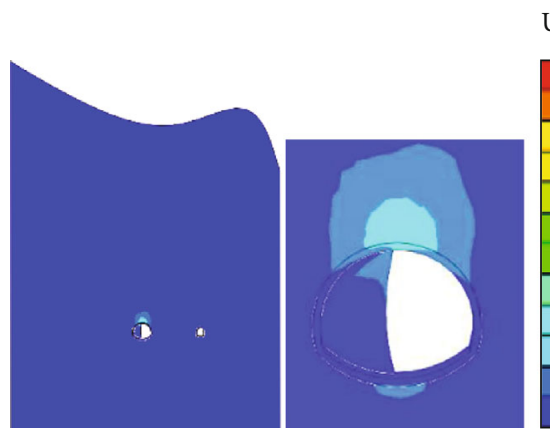

$\mathrm{U}$, magnitude

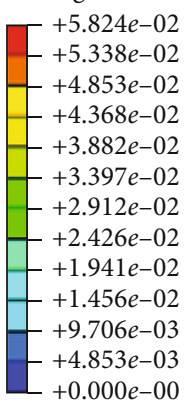

(f)

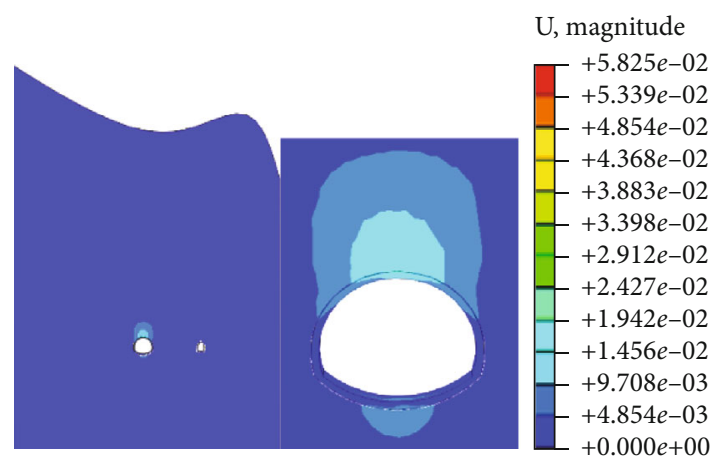

(h)

FIGURE 8: Stress diagram and displacement diagram of the CD method: (a) step 19: excavation stress diagram and partial enlarged drawing, (b) step 21: excavation stress diagram and partial enlarged drawing, (c) step 23: excavation stress diagram and local enlarged drawing, (d) step 25: excavation stress diagram and partial enlarged drawing, (e) step 19: excavation displacement diagram and partial enlarged drawing, (f) step 21: excavation displacement diagram and partial enlarged drawing, (g) step 23: excavation displacement diagram and partial enlarged drawing, and (h) step 25: excavation displacement diagram and partial enlarged drawing. 
TABLE 4: Stress and displacement of surrounding rock.

\begin{tabular}{|c|c|c|c|c|}
\hline \multirow{3}{*}{$\begin{array}{l}\text { Tunnel excavation method } \\
\text { Full-face excavation method }\end{array}$} & \multicolumn{2}{|c|}{ Mises stress $(\mathrm{MPa})$} & \multicolumn{2}{|c|}{ Magnitude displacement (mm) } \\
\hline & Maximum & 6.35 & Vault & -37.58 \\
\hline & Minimum & 0.32 & Invert bottom & 15.47 \\
\hline \multirow{2}{*}{ Bench cut method } & Maximum & 7.20 & Vault & -20.93 \\
\hline & Minimum & 0.57 & Invert bottom & 8.03 \\
\hline \multirow{2}{*}{ CD method } & Maximum & 18.52 & Vault & -15.25 \\
\hline & Minimum & 0.37 & Invert bottom & 7.61 \\
\hline
\end{tabular}

Note: “-" indicates the displacement in the direction of gravity.

operation space, and convenient operation of large mechanical equipment, and its construction speed is obviously better than that of the CD method. Therefore, the bench cut method is widely used in class III and IV surrounding rock with good stability. In the weak surrounding rock of grades IV and V, if the bench cut method is to be used, appropriate advance supporting measures must be selected before excavation to ensure the safety of construction.

\section{Onsite Monitoring and Stability Protection Measures}

5.1. Monitoring of the Liujiazhuang Tunnel Project. The basis for this project monitoring scheme is Technical Code for High Speed Railway Engineering Monitoring (DB11/4902007), Code for Design of High Speed Railway (trial 2009), Technical Specification for Monitoring Measurement of Railway Tunnel. Considering the requirements of Liujiazhuang tunnel monitoring scheme and the actual geological situation of tunnel exit, the layout of vault monitoring points, side wall convergence monitoring points, and inverted arch monitoring points of the Liujiazhuang tunnel is shown in Figure 9.

According to the numerical simulation results of Liujiazhuang tunnel in the previous chapter, D1K923 $+870 \sim \mathrm{D} 1 \mathrm{~K} 923+660$ section is selected for data analysis of monitoring and measurement.

5.1.1. Analysis on Settlement Monitoring Data of Vault of Primary Support. Vault settlement is an important monitoring measurement item in monitoring measurement. The displacement of surrounding rock is related to many factors, and it is a comprehensive index, which can reflect the joint effect of stress, surrounding rock structure, construction method, construction quality, support strength, and other factors. The vault settlement data of the initial supporting of the D1K923+770 D1K923+730 section are analyzed.

According to Figure 10, the monitoring data of five cross-section points show that the stability of surrounding rock takes about 45 days, and the final settlement of each monitoring point is $80.02 \mathrm{~mm}, 85.62 \mathrm{~mm}, 83.79 \mathrm{~mm}$, $88.02 \mathrm{~mm}$, and $122.13 \mathrm{~mm}$, respectively. The D1K923+650 section is the fracture surface before crossing the coal seam, and the final settlement of surrounding rock is basically stable at about $85.0 \mathrm{~mm}$. The D1K923+660 section is the fracture surface crossing the coal seam, and the displacement of $122.12 \mathrm{~mm}$ occurred in the D1K923+660 section. At this

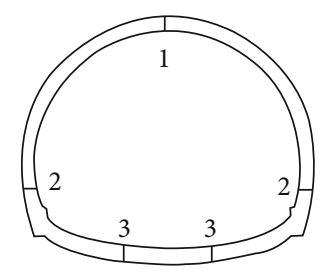

FIGURE 9: Layout of monitoring points for vault, arch waist and inverted arch: point 1: settlement monitoring point of vault, point 2: convergence monitoring point of side wall, and point 3: settlement monitoring point of inverted arch.

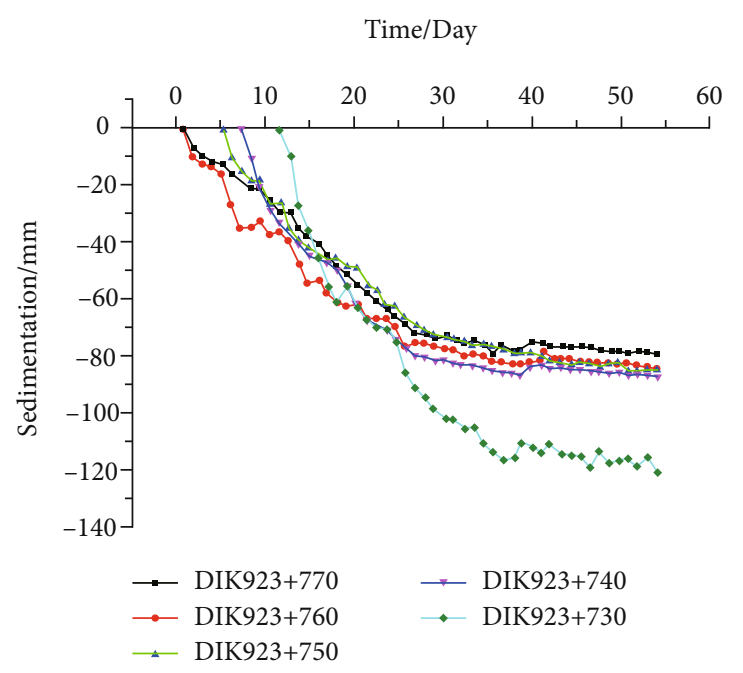

FIGURE 10: Settlement curve of vault.

time, we should increase the monitoring frequency, pay close attention to the development trend of surrounding rock, and ensure the construction safety.

\subsubsection{Analysis of Convergence Monitoring Data of Side Wall.} The convergence monitoring measurement data of side wall of the D1K923+770 D1K923+730 section are analyzed below.

It can be seen from Figure 11 that the final settlement values of each monitoring point are $12.4 \mathrm{~mm}, 12.5 \mathrm{~mm}$, $14.7 \mathrm{~mm}, 16.08 \mathrm{~mm}$, and $16.65 \mathrm{~mm}$, respectively. The final settlement of surrounding rock is basically stable at about $15.0 \mathrm{~mm}$, and the five monitoring sections tend to be stable 


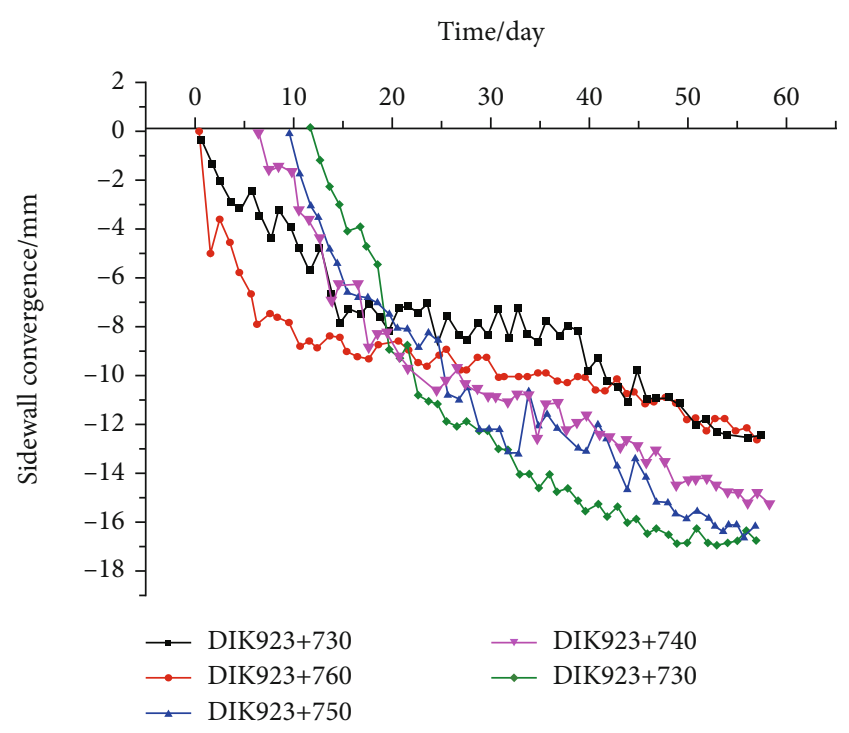

Figure 11: Convergence curve of side wall.

in about 45 days. Through the comparative analysis of five monitoring sections, it is known that with the excavation of the tunnel, the final convergence value changes about $15 \mathrm{~mm}$. It can be seen that the influence of coal seam excavation on the convergence of side wall is not obvious.

\subsubsection{Analysis of Settlement Monitoring Data of Inverted} Arch. The settlement monitoring data of inverted arch of D1K923+770 D1K923+730 section are analyzed below.

It can be seen from Figure 12 that the final settlement values of each monitoring point are $26.97 \mathrm{~mm}, 28.20 \mathrm{~mm}$, $31.00 \mathrm{~mm}, 33.00 \mathrm{~mm}$, and $36.50 \mathrm{~mm}$, respectively. The final settlement of surrounding rock is basically stable at about $35.0 \mathrm{~mm}$, and the five monitoring sections tend to be stable in about 45 days.

The D1K923+740 section is the fracture surface before crossing the coal seam, and the final settlement of surrounding rock is basically stable at about $33.00 \mathrm{~mm}$. The D1K923+730 section is the fracture surface crossing the coal seam, the inverted arch settlement is $36.50 \mathrm{~mm}$, and the variation is small. This is because at the D1K923 +730 section, the coal seam and the tunnel are inclined and intersected, the upper part of the tunnel vault is excavated to the coal seam, and the lower part of the tunnel arch bottom is not excavated to the coal seam; so, the settlement change of the lower part of the tunnel is small.

5.1.4. Monitoring Data Analysis of Pressure Cell and Strain Gauge. From Figures 13 and 14, it can be seen that the internal force of steel arch frame and surrounding rock pressure is basically stable in about 15 days. The D1K923+740 section is the fracture surface before crossing the coal seam, the pressure of surrounding rock is about $0.16 \mathrm{MPa}$, and the internal force of steel arch is $9.8 \mathrm{MPa}$. The $\mathrm{D} 1 \mathrm{~K} 923+730 \mathrm{sec}-$ tion is the fracture surface crossing the coal seam, the pressure of surrounding rock is about $0.21 \mathrm{Mpa}$, and the internal force of steel arch is $10.48 \mathrm{Mpa}$. In the section of

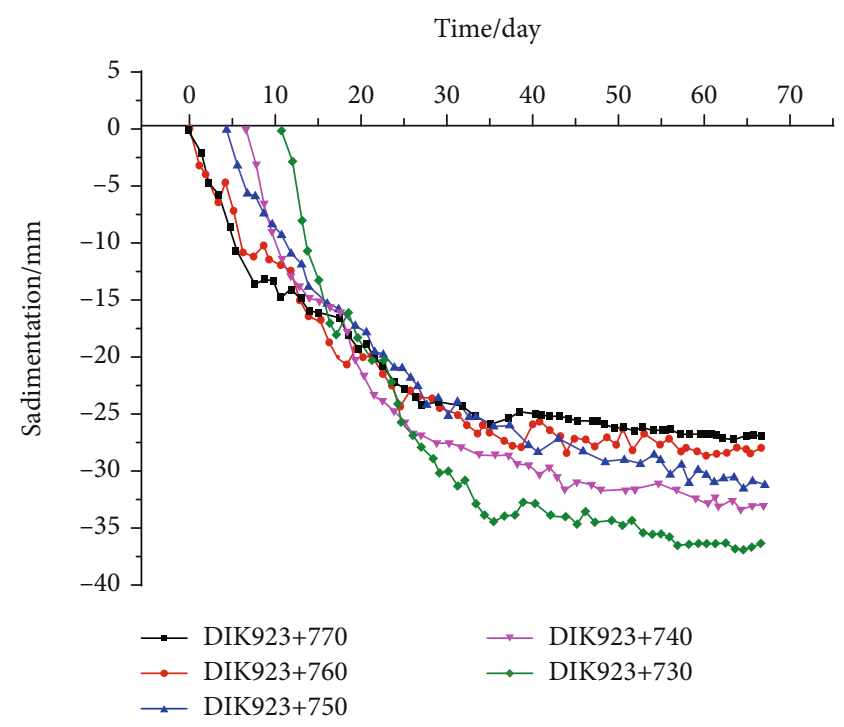

FIgURE 12: Settlement curve of inverted arch.

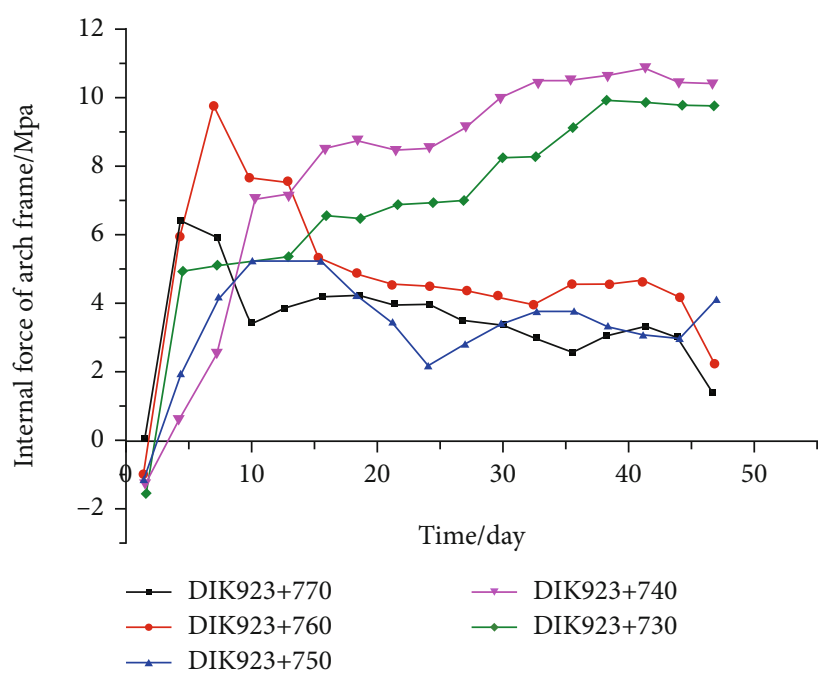

FIGURE 13: Internal force curve of steel arch.

crossing coal seam, the pressure of surrounding rock and the internal force of steel arch frame increases obviously. Therefore, it is necessary to strengthen the monitoring and measurement frequency during the construction to ensure the construction safety.

5.2. Comparative Analysis of Numerical Simulation and Monitoring Results. Through the numerical simulation, we can not only understand the dynamic change law of surrounding rock but also combine the numerical simulation value with the field monitoring data, which can more effectively guide the field construction.

It can be seen from Table 5 that

(1) The numerical simulation values of vault settlement, horizontal convergence, and inverted arch settlement of the D1K923+730 section are $37.58 \mathrm{~mm}$, 


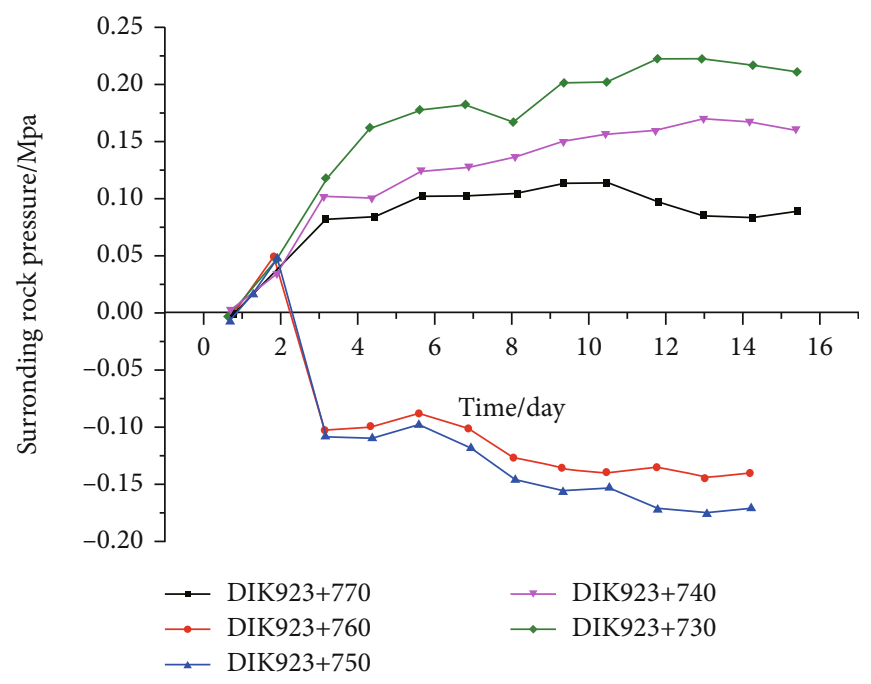

FIgURE 14: Pressure-time curve of surrounding rock.

TABLE 5: Field monitoring value and numerical simulation value.

\begin{tabular}{lcc}
\hline Measurement items & Field monitoring value $(\mathrm{mm})$ & Numerical simulation value $(\mathrm{mm})$ \\
\hline Settlement displacement of vault & 61.2 & 37.58 \\
Horizontal convergence displacement & 7.5 & 2.29 \\
Settlement displacement of inverted arch & 18.2 & 15.47 \\
\hline
\end{tabular}

Note: this table shows the measured and simulated values of the D1K923+730 section.

$2.29 \mathrm{~mm}$, and $15.47 \mathrm{~mm}$, respectively. The simulation value of ABAQUS software is smaller than the measured value, which is because the mechanical parameters used in the numerical model are from the geological exploration report, which is within a range of statistical result. Compared with the actual mechanical parameters of the surrounding rock, the parameters used in numerical model to a certain extent cannot correctly reflect the stress-strain relationship of the actual surrounding rock in the process of excavation. Therefore, there is a gap between the deformation convergence results of numerical simulation and the convergence values of field monitoring. However, the convergence trend of surrounding rock obtained from numerical simulation and field measurement is consistent; so, the results of numerical simulation can be used to describe the law of tunnel convergence after tunnel excavation

(2) Onsite monitoring and measurement should be used to design the key parts of tunnel surrounding rock and supporting structure, so as to ensure the economy and safety of engineering construction

(3) In actual construction, if the measured value is greater than the predicted value, the construction should be slowed down or stopped, and the design parameters of supporting structure should be enhanced. If the measured value is less than or equal to the predicted value, it shows that the design parameters of the surrounding rock support structure are reasonable, the construction method is feasible, and the normal construction can continue

\section{Discussions}

For the tunnel with weak surrounding rock, from the perspective of deformation control, the selection of appropriate "support time" and "support stiffness" plays an important role in the stability of the tunnel. Therefore, through the optimization analysis of Liujiazhuang tunnel construction process and scheme, the following deformation control measures are proposed.

(1) Reasonable selection of excavation division and excavation footage can effectively change the stress and deformation of surrounding rock and supporting structure and prevent tunnel instability

(2) With the excavation of the tunnel, the weak surrounding rock has a large deformation in the face and in front of the face. If not controlled, it will cause partial collapse and large deformation of the vault of the face and then result into the secondary disasters of the surrounding rock. During tunnel construction, the reinforcement measures behind the tunnel face 
cannot control the deformation of surrounding rock in front of the tunnel face. Therefore, the advanced support technology with auxiliary measures can effectively control the construction deformation of weak surrounding rock tunnel and ensure the construction safety

\section{Conclusions}

Based on the project of the Liujiazhuang tunnel exit section of Shanghai-Kunming Passenger Dedicated Line, large-scale finite element software ABAQUS is used to simulate the excavation of large section tunnel in weak surrounding rock and the construction process when crossing coal seam. Through the simulation of the site construction scheme and three different excavation methods, we obtained the variation law of stress and strain of surrounding rock and supporting structure. The field monitoring measurement data and numerical simulation results of tunnel vault settlement, sidewall convergence, inverted arch settlement, surrounding rock pressure, and support internal force are compared and analyzed, and the following conclusions are obtained:

(1) With the excavation of the tunnel, when palm surface passes through the coal seam, the simulated displacement and stress using bench method increase abruptly. The maximum stress of the supporting structure is $18.13 \mathrm{MPa}$ when crossing the coal seam, and the maximum displacement reaches $45 \mathrm{~mm}$, which is about twice the displacement without crossing the coal seam. Therefore, normally, the tunnel can be constructed according to the bench method without crossing the coal seam, and the design parameters of the supporting structure should be enhanced when crossing the coal seam

(2) By the comparison of the three construction methods, it can be known that cavern settlement is the largest, and the stress is the smallest under the full-face construction method. The maximum settlement of the step method is 0.57 times of the maximum settlement of the whole section, and the maximum stress of the bench method is 0.39 times of the CD method. Therefore, the bench method can better control the stability of excavation face; furthermore, in the case of allowing large settlement, the technical and economic benefits of the bench method are better than the benefits of the CD method

(3) Through the comparative analysis of onsite monitoring and numerical calculation of tunnel vault settlement, horizontal convergence of side wall, and tunnel invert settlement data of the Liujiazhuang Tunnel, it can be seen that the tunnel is in a dangerous state when crossing the coal seam section. Engineering measures such as strengthening support or the bench method with auxiliary measures of advanced support should be taken immediately to control the deformation of surrounding rock and ensure the construction safety

\section{Data Availability}

The data used to support the findings of this study are included within the article.

\section{Conflicts of Interest}

The authors declare that they have no conflicts of interest.

\section{Acknowledgments}

This work was financially supported by the National Natural Science Foundation of China (41807254), Key Research \& Development and Promotion Projects of Henan Province (212102310374), China Postdoctoral Science Foundation (2020M682372), and Young Talent Support Project of Henan Province (2021HYTP013). We would like to express our sincerest gratitude to the help of Yanzong Cui of North China University of Water Resources and Electric Power for field data collection and analysis.

\section{References}

[1] T. Zhigang, Z. Fei, W. Hongiian, Z. Haijiang, and P. Yanyan, "Innovative constant resistance large deformation bolt for rock support in high stressed rock mass," Arabian Journal of Geosciences, vol. 10, no. 15, 2017.

[2] S. Tian, Y. Zhao, S. Shi, and J. Hu, "The status problems and countermeasures of typical disaster prevention and control methods during the construction period of Chinese railway tunnels," Hazard Control in Tunnelling and Underground Engineering, vol. 1, no. 2, pp. 24-48, 2019.

[3] Z. He, "Analysis of geological problems of railway tunnels: case study of typical tunnels," Tunnel Construction, vol. 36, no. 6, pp. 636-665, 2016.

[4] D. Li, Y. Lu, Y. Rong et al., "Rapid uncovering seam technologies for large cross-section gas tunnel excavated through coal seams using directional hydraulic fracturing," Rock and Solid Mechanics, vol. 40, no. 1, pp. 363-369, 2019.

[5] S. Li, K. Wang, and L. Li, "Mechanical mechanism and development trend of water inrush disasters in karst tunnels," Chinese Journal of Theoretical and Applied Mechanics, vol. 49, no. 1, pp. 22-30, 2017.

[6] G. Zhang, J. Deng, and D. Wang, "Mechanism and classification of tectonic-induced large deformation of soft rock tunnels," Advanced Engineering Sciences, vol. 53, no. 1, pp. 1-12, 2021.

[7] Y. Wang, C. Li, and J. Han, "On the effect of stress amplitude on fracture and energy evolution of pre- flawed granite under uniaxial increasing-amplitude fatigue loads," Engineering Fracture Mechanics, vol. 240, article 107366, 2020.

[8] Y. Wang, Y. Yi, C. Li, and J. Han, "Anisotropic fracture and energy characteristics of a Tibet marble exposed to multilevel constant-amplitude (MLCA) cyclic loads: a lab-scale testing," Engineering Fracture Mechanics, vol. 244, article 107550, 2021.

[9] Z. Tao, C. Zhu, M. He, and M. Karakus, "A physical modelingbased study on the control mechanisms of negative Poisson's ratio anchor cable on the stratified toppling deformation of anti- inclined slopes," International Journal of Rock Mechanics and Mining Sciences, vol. 138, article 104632, 2021. 
[10] X. Yang, L. Li, and B. Liu, "Evaluation on structure stability of unsymmetrically tunnels using the theory of information optimization analysis," Chinese Journal of Rock Mechanics and Engineering, no. 4, pp. 484-488, 2002.

[11] G. Liu, F. Zhang, X. Li, and Z. Yang, "Research on large deformation and its mechanism of Muzhailing tunnel," Chinese Journal of Rock Mechanics and Engineering, Supplement 2, pp. 5521-5526, 2005.

[12] Q. Zuo, L. Wu, Z. Lu, Y. Tan, and Q. Yuan, "Instability analysis of soft surrounding rock in shallow tunnel portal under unsymmetrical pressure by catastrophe theory," Rock and Soil Mechanics, vol. 36, Supplement 2, pp. 424-430, 2015.

[13] D. A. Yong-hao, C. H. Wei-Zhong, and T. I. Hong-ming, "Study of large deformation and support measures of daliang tunnel with soft surrounding rock mass," Chinese Journal of Rock Mechanics and Engineering, vol. 34, Supplement 2, pp. 4149-4156, 2015.

[14] Y. Peng, L. Wu, H. Peng, Y. Hao, and Y. An, “Theoretical and experimental study on rock resistance coefficient of soft rock tunnel considering creep effect," Arabian Journal for Science and Engineering, vol. 45, no. 5, pp. 4333-4342, 2020.

[15] X. Li, D. Li, X. Jin, and Y. Gu, "Discussion on influence of initial support to stability and deformation of surrounding rock mass in soft rock tunnel," Rock and Soil Mechanics-WUHAN, no. 8, pp. 1207-1210, 2005.

[16] Z. Liu, W. Li, Y. Zhu, and M. Sun, "Research on construction time of secondary lining in soft rock of large-deformation tunnel," Chinese Journal of Rock Mechanics and Engineering, vol. 27, no. 3, pp. 580-588, 2008.

[17] K. Tan, Q. Yang, and L. Yang, "Effect of uneven pressure and heterogeneous ground on the safety and stability of twin tunnels with small spacing," Modern Tunnelling Technology, vol. 47, no. 4, pp. 20-26, 2010.

[18] H. Wang, P. Su, H. Sun, K. Qi, and J. Shao, "Prediction of ground settlement caused by shield construction in soft rock ground," Chinese Journal of Rock Mechanics and Engineering, vol. 39, Supplement 2, pp. 3549-3556, 2020.

[19] W. Dai, "Numerical analysis on stability of retaining scheme comparison and selection for shallow tunnel under unsymmetrical pressure," Railway Engineering, no. 3, pp. 61-65, 2011.

[20] C. Yang, Y. Zhang, D. Huang, and Y. Lou, "A study of tunnel surrounding rock stability of shallow and unsymmetrical loaded portal section with excavation sequences from inside," Hydrogeology and Engineering Geology, vol. 39, no. 4, pp. 4954, 2012.

[21] S. Chen, Y. Zhu, Z. Li, L. Huang, and H. Zhang, "Analysis of lateral slope stability during construction of a loess tunnel with a large section," Modern Tunnelling Technology, vol. 51, no. 1, pp. 82-89, 2014.

[22] S. Wu, Y. Gan, Y. Ren, and L. Zheng, "Feasibility research of AE monitoring index in tunnel based on RA and AF," Chinese Journal of Engineering, vol. 42, no. 6, 730 pages, 2020.

[23] H. Wang, F. Zhao, Z. Huang, Y. Yao, and G. Yuan, "Experimental study of mode-I fracture toughness for layered shale based on two ISRM-suggested methods," Rock Mechanics and Rock Engineering, vol. 50, no. 7, pp. 1933-1939, 2017.

[24] H. Wang, D. Liu, Z. Cui, C. Cheng, and Z. Jian, "Investigation of the fracture modes of red sandstone using XFEM and acoustic emissions," Theoretical and Applied Fracture Mechanics, vol. 85, pp. 283-293, 2016.
[25] G. Hou, Z. Li, T. Hu et al., "Study of tunnel settlement monitoring based on distributed optic fiber strain sensing technology," Rock and Soil Mechanics, vol. 41, no. 9, pp. 3148-3158, 2020.

[26] L. Liu, F. Wu, G. Zhang, and Y. Bai, "Research and application of tunnel construction monitoring method based on dynamic 3D parametric modelling technology," Modern Tunnelling Technology, vol. 57, Supplement 1, pp. 859-863, 2020. 